\title{
ENCOLHIMENTO NA SECAGEM CONVECTIVA DE ABACAXI COM APLICAÇÃO DE MICRO-ONDAS VARIÁ VEL
}

\author{
F. J. LOPES ${ }^{1 *}$, N. R. PEREIRA ${ }^{2}$ \\ ${ }^{1}$ Universidade Federal de Lavras, Departamento de Ciências dos Alimentos \\ ${ }^{2}$ Universidade Estadual do Norte Fluminense Darcy Ribeiro, Centro de Ciências e Tecnologias \\ Agropecuárias. \\ *e-mail:francemirlopes@yahoo.com.br
}

\begin{abstract}
RESUMO
A aplicação de micro-ondas na secagem de produtos alimentícios, quando controlada, acelera a cinética de secagem e pode reduzir o encolhimento e as alterações estruturais responsáveis pela redução de qualidade de alimentos desidratados. O presente trabalho teve como objetivo estudar a cinética de encolhimento de abacaxi secos, utilizando energia de micro-ondas-convectivo, avaliando a influência das condições do ar e energia aplicadas no início e no final do processo. O processo de secagem foi dividido em dois períodos (I e II). A potências de micro-ondas aplicadas ao processo foram de 0,2, 0,4 e $0,65 \mathrm{~W} / \mathrm{g}$ com referência à massa inicial da fruta. Os testes de secagem foram realizados com temperaturas do ar quente a $55{ }^{\circ} \mathrm{C}$ e $70{ }^{\circ} \mathrm{C}$ e vazão de ar fixado em $0,5 \mathrm{~m}^{3} / \mathrm{min}$. Os resultados foram analisados estatisticamente pelo programa empregando-se a análise de variância utilizando o teste Tukey, ao nível de $5 \%$ de significância $(\mathrm{p}<0,05)$. Os resultados mostraram que o encolhimento foi linear com o decréscimo de umidade. $\mathrm{O}$ menor encolhimento foi observado em temperaturas do ar fixada a $55^{\circ} \mathrm{C}$ e potência de micro-ondas de $260 \mathrm{~W}$ aplicadas no período I e $260 \mathrm{~W}$ no período II. O encolhimento maior foi obtido quando diminui a potência de micro-ondas de $170 \mathrm{~W}$ do período I para $90 \mathrm{~W}$ no período II com temperaturas de $70{ }^{\circ} \mathrm{C}$. Os resultados sugerem que o controle da temperatura do ar e da potência de micro-ondas no primeiro período de secagem pode ser utilizado para se obter um produto de boa qualidade.
\end{abstract}

\section{INTRODUÇÃO}

O abacaxizeiro (Ananas comosus L) é uma planta monocotiledônea perene, pertencente à família Bromeliaceae (REINHARDT, 2000).

O abacaxi apresenta grande aceitação tanto pelos consumidores brasileiros quanto pelos estrangeiros, devido a suas características físico-químicas (THÉ et al., 2010). Tem sido a fruta não cítrica mais popular nos países tropicais e subtropicais, principalmente pelo seu atrativo sabor e aroma, contendo uma grande diversidade de vitaminas e sais minerais (ALMEIDA et al., 2004).

O Brasil é um dos grandes produtores mundiais de abacaxi. Entretanto, devido à alta perecibilidade da fruta, o país sofre com as perdas pós-colheita, decorrentes da sazonalidade da produção e da distância dos mercados consumidores, adicionados ainda à ausência de tratamentos e ao manuseio póscolheita eficiente, dificultando o escoamento da produção e seu consumo in natura. De modo geral, os as frutas encolhem durante a secagem, e este encolhimento proporciona uma redução no custo da embalagem do 
produto final, facilitando seu armazenamento e transporte. Entretanto, o encolhimento é um dos fatores responsáveis pela perda de qualidade de alimentos desidratados. $\mathrm{O}$ conhecimento da influência das variáveis do processo de secagem sobre o encolhimento é essencial para melhorar a compreensão da cinética de secagem, bem como para a preservação da qualidade do produto.

A aplicação de micro-ondas na secagem de produtos alimentícios, quando controlada, acelera a cinética de secagem, como o observado por (BOTHA; OLIVEIRA; AHRNÉ, 2012; FENG; YIN; TANG, 2012; FIGIEL, 2009; KONÉ et al., 2013) sendo que o produto processado pode atingir qualidade superior àquela obtida pelos métodos convencionais. Em contrapartida, o fenômeno do encolhimento durante o processo de secagem ainda não está totalmente esclarecido.

O presente trabalho teve como objetivo estudar a cinética de encolhimento de abacaxi secos, utilizando secagem convectiva combinada com micro-ondas, avaliando a influência das condições do ar e aplicação variável de micro-ondas no encolhimento do produto.

\section{MATERIAL E METODOS}

As amostras de abacaxis firmes e maduros da cultivar pérola (Ananas comosus) foram fornecidas por único produtor, do município de São João da Barra - RJ. Os abacaxis foram escolhidos de acordo com seu grau de maturação, pela coloração da casca, e pelo teor de sólidos solúveis totais (entre 10 e $15^{\circ}$ Brix).

\subsection{Preparo das amostras}

Os frutos foram descascados manualmente até a remoção completa da casca. Os miolos foram removidos e a polpa foi cortada em pedaços cilíndricos com 25 $\mathrm{mm}$ de diâmetro e $10 \mathrm{~mm}$ de espessura com o auxílio de um cortador projetado para este fim. Os abacaxis tinham em média $166 \mathrm{~cm}$ de comprimento, $123 \mathrm{~cm}$ de largura e pesavam em média $1,359 \mathrm{Kg}$, desconsiderando a coroa.

\subsection{Volume aparente e encolhimento}

$\mathrm{O}$ volume aparente das amostras foi medido por análise de imagem digital. As amostras foram fotografadas no mesmo instante em que foram pesadas. A área superficial foi medida diretamente pelas fotografias, por meio de cinco amostras diferentes. A espessura das mesmas foi determinada por meio de uma média aritmética das medidas realizadas em cinco diferentes pontos da amostra, como demonstrado na Figura 1, com a utilização de um paquímetro. Esta análise foi repetida em 5 amostras diferentes.

Figura 1 - Pontos de medição da espessura ao longo da amostra de abacaxi.

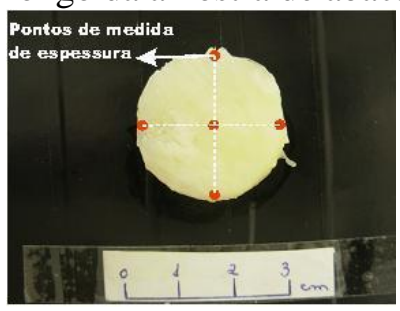

A análise de imagem foi realizada pelo tratamento de 5 amostras por meio do software livre ImageJ para obtenção da área superficial. O software livre ImageJ relaciona o tamanho do objeto na imagem ao tamanho no mundo real, por isso a importância da escala da imagem. Ao capturar as imagens e salva-las no computador o software é capaz de converter o número de pixels dos pedaços de abacaxi para as dimensões reais. Os dados de volume aparente foram obtidos multiplicando-se a área superficial fotografada pela espessura média do material em cada tempo de secagem.

O encolhimento (S) foi calculado como sendo a relação entre o volume aparente da amostra seca $\left(\mathrm{V}_{\mathrm{d}}\right)$ e o seu volume aparente inicial $\left(\mathrm{V}_{0}\right)$, Equação 1. Foram feitas marcações na bandeja, para obter o volume 
aparente das mesmas amostras durante a secagem.

$$
\mathrm{S}=\frac{\mathrm{V}_{\mathrm{d}}}{\mathrm{V}_{0}} \times 100
$$

Figura 2- a) Imagem original dos pedaços de abacaxi in natura (esquerda) e depois do tratamento (direita), b) Imagem original dos pedaços de abacaxi seco (esquerda) e depois do tratamento (direita).
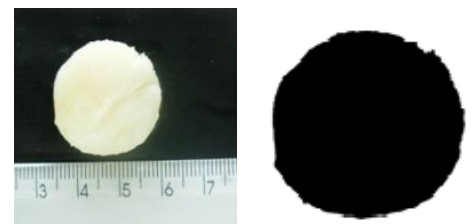

(a)
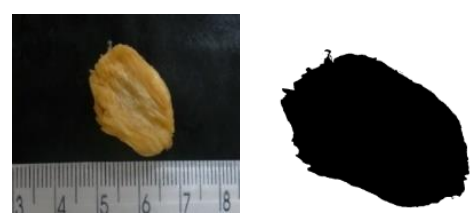

(b)

\subsection{Cinética de encolhimento}

A cinética de encolhimento foi realizada pelo acompanhamento das variações de volume aparente e área superficial das amostras em relação à amostra in natura, medidos por imagem digital conforme descrito anteriormente. A espessura e as imagens das amostras foram coletadas a cada 15 minutos de secagem nos primeiros 30 minutos e a cada 10 minutos no restante do processo até atingir massa correspondente a $15 \%$ de umidade.

\subsection{Análise estatística}

Os dados obtidos do encolhimento foram analisados estatisticamente pelo programa estatístico SAS - Statistical Analysis System (2003), versão 9.3, empregando-se a análise de variância (ANOVA) utilizando o teste Tukey, ao nível de $5 \%$ de significância $(\mathrm{p}<0,05)$.

\subsection{Secagem assistida por micro-ondas}

\subsubsection{Forno de micro-ondas adaptado}

Para a realização do processo de secagem assistida a micro-ondas, os experimentos foram conduzidos em um forno doméstico a micro-ondas, da marca Brastemp, cavidade com volume de 38 litros, modelo BMC38-A, com $900 \mathrm{~W}$ de potência nominal máxima, devidamente adaptado a um sistema de ar quente no Laboratório de Tecnologia de Alimentos (LTA/CCTA/UENF). A montagem do equipamento foi desenvolvida de acordo com (SILVA et al., 2011).

\subsection{Procedimento experimental}

$O$ processo de secagem foi dividido em dois períodos (I e II) como ilustrado na Tabela 1. No período I, o processo de secagem foi conduzido até que as amostras atingissem um teor de umidade de $40 \%$ (bu), enquanto no período II, o processo foi realizado entre $40 \%$ a $15 \%$ de umidade (bu). A potências de micro-ondas aplicadas ao processo foram de 90,170 e $259 \mathrm{~W}$, correspondentes a $0,2,0,4$ e $0,65 \mathrm{~W} / \mathrm{g}$ com referência à massa inicial da fruta. Os testes de secagem foram realizados com temperaturas do ar quente a $55^{\circ} \mathrm{C}$ e $70{ }^{\circ} \mathrm{C}$ e vazão de ar fixado em $0,5 \mathrm{~m}^{3} / \mathrm{min}$.

O período I foi conduzido com duas diferente potência de micro-ondas e temperatura do ar, $170 \mathrm{~W}$ e $260 \mathrm{~W}$, e $70{ }^{\circ} \mathrm{C}$ e $55{ }^{\circ} \mathrm{C}$, respectivamente. Essas condições foram escolhidas visando acelerar o período de indução térmica, de maneira que tanto o ar quanto as micro-ondas forneçam energia para o material. Neste período as amostras foram secas até aproximadamente $40 \%$ de umidade (bu).

No período II de secagem, aplicou-se $90 \mathrm{~W}$ e $260 \mathrm{~W}$ de potência e as mesmas condições de temperatura do ar aplicadas no período I $\left(70{ }^{\circ} \mathrm{C}\right.$ e $\left.55^{\circ} \mathrm{C}\right)$, e foi conduzido até que o produto atingisse, aproximadamente, $15 \%$ de umidade (bu). A partir do período I, correspondente a $40 \%$ de umidade (bu), a secagem do abacaxi torna-se mais lenta e é considerado o período critico da secagem. 
Tabela 1 - Esquema ilustrativo das condições experimentais testadas para secagem com aplicação de micro-ondas variável dos pedaços de abacaxi.

\begin{tabular}{ccc}
\cline { 2 - 3 } & Período I & Período II \\
\hline $\mathrm{T}^{\circ} \mathrm{C}$ & $\mathrm{P}(\mathrm{W})$ & $\mathrm{P}(\mathrm{W})$ \\
\hline \multirow{2}{*}{$55^{\circ} \mathrm{C}$} & 170 & 90 \\
& 260 & 260 \\
\hline \multirow{3}{*}{$70{ }^{\circ} \mathrm{C}$} & 170 & 90 \\
& 170 & 260 \\
& 260 & 260 \\
\hline
\end{tabular}

\section{RESULTADOS E DISCUSSÃO}

A aplicação de potência de micro-ondas variável durante o processo de secagem não alterou o comportamento linear do encolhimento dos pedaços de abacaxi. Uma excelente concordância também foi encontrada entre os dados experimentais e os previstos por ajuste linear $\left(\mathrm{R}^{2} \geq 0,9888\right)$ para o período I e $\left(\mathrm{R}^{2}=1\right)$ no período II. Resultados semelhantes foram encontrados por (RUIZ-LÓPEZ et al., 2012). O encolhimento foi observado em todas as condições de processo conforme mostrado na Figura 3 e 4 . Observa-se que houve uma tendência da elevação da potência proporcionar aumento de $\mathrm{V} / \mathrm{V}_{0}$.

$\mathrm{O}$ menor encolhimento foi observado em temperaturas do ar fixada a $55{ }^{\circ} \mathrm{C}$ e potência de micro-ondas de $260 \mathrm{~W}$ aplicadas no período I e $260 \mathrm{~W}$ no período II. Este resultado diferiu estatisticamente ao nível de $(\mathrm{p}<0,05)$ pelo teste de tukey dos obtidos pelas outras condições, exceto para temperaturas do ar e potência de micro-ondas fixas em $70{ }^{\circ} \mathrm{C}$ e $170 \mathrm{~W}$ no período I e 260 e $90 \mathrm{~W}$ no período II (Tabela 2). O encolhimento maior foi obtido quando diminui a potência de micro-ondas de $170 \mathrm{~W}$ do período I para $90 \mathrm{~W}$ no período II com temperaturas de $70{ }^{\circ} \mathrm{C}$. Em temperaturas do ar fixas em $55^{\circ} \mathrm{C}$, as variações da potência de micro-ondas não diferiram significativamente na redução do volume entre si. Os mesmos efeitos foram observados para temperatura do ar de $70^{\circ} \mathrm{C}$.

Tabela 2 - Médias do encolhimento $\left(\mathrm{V} / \mathrm{V}_{0}\right)$ dos pedaços de abacaxi seco.

\begin{tabular}{lc}
\hline Experimento & $\mathrm{V} / \mathrm{V}_{0}$ \\
\hline $70{ }^{\circ} \mathrm{C}-170 \mathrm{~W}-90 \mathrm{~W}$ & $0,09^{\mathrm{b}} \pm 0,01$ \\
$70{ }^{\circ} \mathrm{C}-166 \mathrm{~W}-260 \mathrm{~W}$ & $0,11^{\mathrm{b}} \pm 0,02$ \\
$70^{\circ} \mathrm{C}-260 \mathrm{~W}-260 \mathrm{~W}$ & $0,12^{\mathrm{ab}} \pm 0,01$ \\
\hline $55^{\circ} \mathrm{C}-170 \mathrm{~W}-90 \mathrm{~W}$ & $0,12^{\mathrm{ab}}+0,01$ \\
$55^{\circ} \mathrm{C}-260 \mathrm{~W}-260 \mathrm{~W}$ & $0,15^{\mathrm{a}} \pm 0,02$ \\
\hline Médias na mesma coluna & acompanhadas de \\
mesma letra não são significativamente diferentes \\
pelo teste de Tukey $(\mathrm{P}<0,05)$.
\end{tabular}

Figura 3 - Encolhimento volumétrico $\left(\mathrm{V} / \mathrm{V}_{0}\right)$ dos pedaços de abacaxi desidratadas em todas as condições de temperatura e potência de microondas variável.

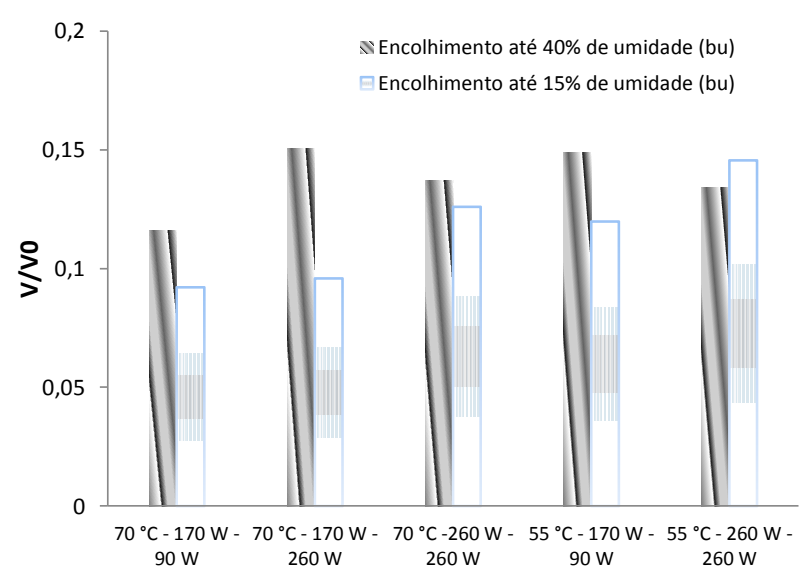

Em baixas umidades foi verificada a estabilização da redução do volume, correspondente ao enrijecimento da parede celular do produto. Esta diminuição da redução do volume no final do processo também foi observada por (YAN; SOUSAGALLAGHER; OLIVEIRA, 2008) ao estudarem o encolhimento de banana, abacaxi e pedaços de manga durante a secagem com ar quente.

(KHRAISHEH; MCMINN; MAGEE, 2004; MAYOR; SERENO, 2004) explicam que 
baixa potência de micro-ondas resulta na diminuição das taxas de secagem, consequentemente, as forças induzidas não são suficientemente fortes para quebrar a estrutura e, por conseguinte, o encolhimento é limitado. Além disso, observaram que o encolhimento é menor na secagem com micro-ondas em comparação à secagem convectiva.
É valido ressaltar que a potência de microondas de $90 \mathrm{~W}$ no período II não favoreceu a obtenção de um produto crocante, mas com aspectos borrachudos, principalmente quando foram aplicadas baixas temperatura do ar de secagem, além de acarretar maior tempo de processo.

Figura 4 - Encolhimento volumétrico $\left(\mathrm{V} / \mathrm{V}_{0}\right)$ dos pedaços de abacaxi desidratado versus umidade adimensional (bs).
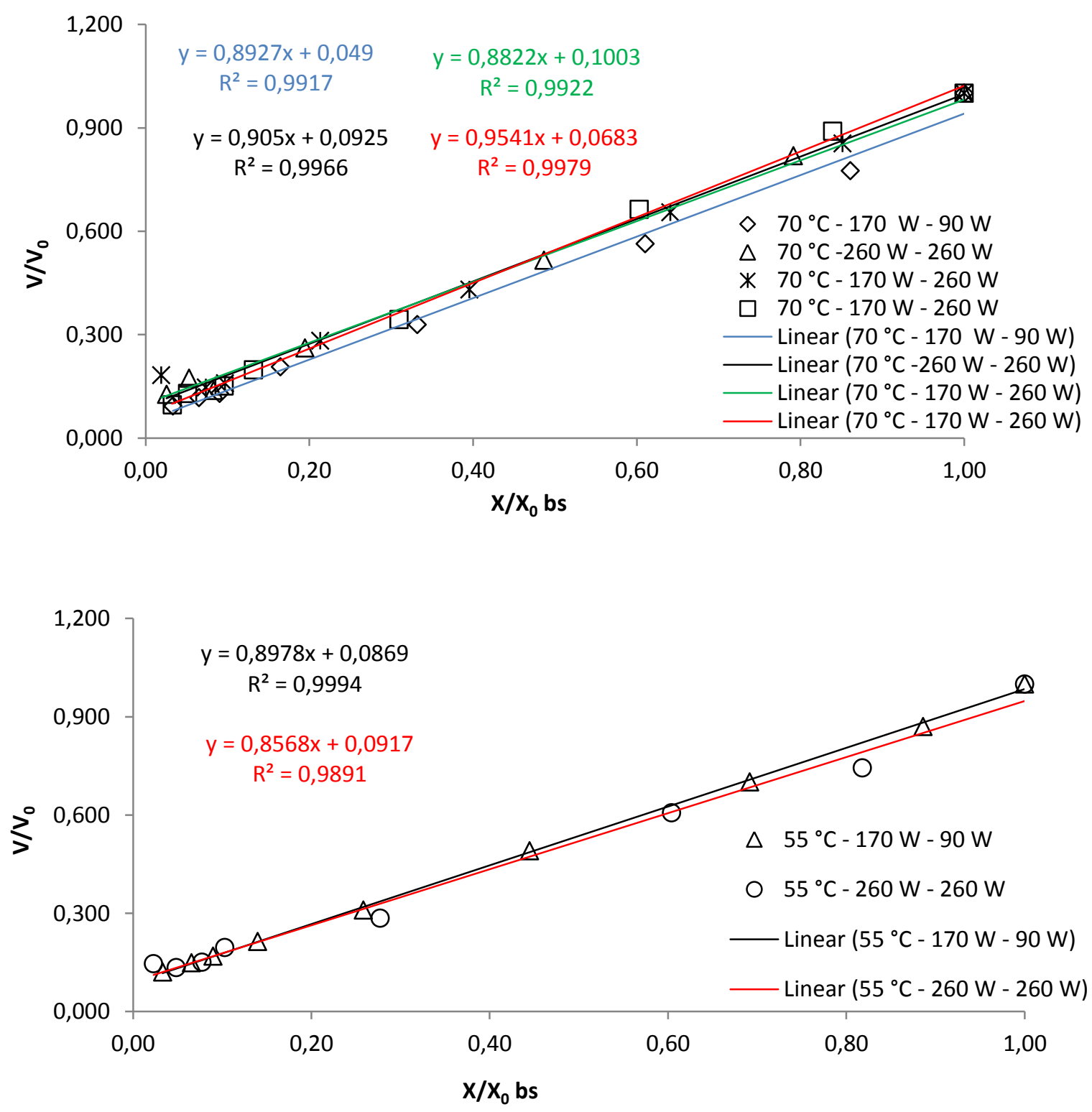


\section{CONCLUSÃO}

O encolhimento foi observado em todas as condições de processo experimentais adotadas e este fenômeno foi linear com o decréscimo de umidade. Entretanto, há indício de que a elevação da potência proporciona aumento de $\mathrm{V} / \mathrm{V}_{0}$, ou seja pode reduzir o encolhimento.

$\mathrm{O}$ menor encolhimento foi observado em temperaturas do ar fixada a $55{ }^{\circ} \mathrm{C}$ e potência de micro-ondas de $260 \mathrm{~W}$ aplicadas no período I e $260 \mathrm{~W}$ no período II.

$\mathrm{O}$ encolhimento maior foi obtido quando diminui a potência de micro-ondas de $170 \mathrm{~W}$ do período I para $90 \mathrm{~W}$ no período II com temperaturas de $70{ }^{\circ} \mathrm{C}$.

Não foi observada influência da temperatura do ar e da potência de microondas no encolhimento do produto no segundo período de secagem.

Portanto, os resultados sugerem que o controle da temperatura do ar e da potência de micro-ondas no primeiro período de secagem pode ser utilizado para se obter um produto de boa qualidade.

\section{NOMENCLATURA}

$\begin{array}{ll}\mathrm{bs} & \text { Base seca } \\ \mathrm{bu} & \text { Base úmida } \\ \mathrm{Dp} & \text { Densidade potência }(w / g) \\ \mathrm{X} / \mathrm{X}_{0} & \text { Umidade adimensional } \\ \mathrm{V} / \mathrm{V}_{0} & \text { Encolhimento volumétrico } \\ \mathrm{PI} & \text { Período I } \\ \mathrm{PII} & \text { Período II } \\ \mathrm{t} & \text { Tempo (min) } \\ \text { Subscritos } & \\ 0 & \text { Referente à condição inicial } \\ \mathrm{f} & \text { Referente à condição final }\end{array}$

\section{REFERÊNCIAS}

ALMEIDA, C. O. de.; VILAR, L. da C.; SOUZA, L. F. da S.; REINHARDT, D. H.; MACEDO, C. M. Peso médio do abacaxi no
Brasil: um tema em discussão. Bahia Agrícola. Bahia citros: fortalecimento da citricultura baiana. Salvador-Seagri, v. 6, n. 3, p. 41-46, 2004.

BOTHA, G. E.; OLIVEIRA, J. C.; AHRNÉ, L. Quality optimisation of combined osmotic dehydration and microwave assisted air drying of pineapple using constant power emission. Food and Bioproducts Processing, v. 90, n. 2, p. 171-179, 2012.

FENG, H.; YIN, Y.; TANG, J. Microwave Drying of Food and Agricultural Materials: Basics and Heat and Mass Transfer Modeling. Food Engineering Reviews, v. 4, n. 2, p. 89106, 2012.

FIGIEL, A. Drying kinetics and quality of vacuum-microwave dehydrated garlic cloves and slices. Journal of Food Engineering, v. 94, n. 1, p. 98-104, 2009.

KHRAISHEH, M. A. M.; MCMINN, W. A. M.; MAGEE, T. R. A. Quality and structural changes in starchy foods during microwave and convective drying. Food Research International, v. 37, n. 5, p. 497-503, 2004.

KONÉ, K. Y., DRUON, C., GNIMPIEBA, E. Z., DELMOTTE, M., DUQUENOY, A., LAGUERRE, J. C. Power density control in microwave assisted air drying to improve quality of food. Journal of Food Engineering, v. 119, n. 4, p. 750-757, 2013.

MAYOR, L.; SERENO, A. M. Modelling shrinkage during convective drying of food materials: a review. Journal of Food Engineering, v. 61, n. 3, p. 373-386, 2004.

REINHARDT, D. A planta e o seu ciclo. Abacaxi. Produção: Aspectos técnicos. Cruz das almas: EMBRAPA Mandioca e Fruticultura, p. 13-14, 2000. 
RUIZ-LÓPEZ, I. I., RUIZ-ESPINOSA, H., ARELLANES-LOZADA, P., BÁRCENASPOZOS, M. E., GARCÍA-ALVARADO, M. A. Analytical model for variable moisture diffusivity estimation and drying simulation of shrinkable food products. Journal of Food Engineering, v. 108, n. 3, p. 427-435, 2012.

SILVA, F. A., GONÇALVES, L. A. G., DAMIANI, C., GONÇALVES, M. Á. B., JÚNIOR, M. S. S., JÚNIOR, A. M. Estabilidade oxidativa de amêndoas de noz macadâmia secas por micro-ondas com ar quente. Pesquisa Agropecuária Tropical, v. 41, n. 2, p. 286-292, 2011.

THÉ, P. M. P.; NUNES, R. de P.; MOREIRA DA SILVA, L. I. M.; ARAÚJO, B. M.de. Características físicas, físico-químicas, químicas e atividade enzimática de abacaxi $\mathrm{cv}$. smooth cayenne recém colhido. Alimentos e Nutrição. V. 21, n. 2, p. 273281. 2010.

YAN, Z.; SOUSA-GALLAGHER, M. J.; OLIVEIRA, F. A. R. Shrinkage and porosity of banana, pineapple and mango slices during air-drying. Journal of Food Engineering, v. 84, n. 3, p. 430-440, 2008.

\section{AGRADECIMENTOS}

Ao Conselho Nacional de Pesquisa e Desenvolvimento Tecnológico - $\mathrm{CNPq}$ e Fundação Carlos Chagas Filho de Amparo à Pesquisa do Estado do Rio de JaneiroFAPERJ, pelo apoio à pesquisa. 